\title{
IDENTITY IN INFORMATION BEHAVIOUR RESEARCH: A CONCEPTUAL ANALYSIS (Paper)
}

\begin{abstract}
Résumé:
Using a conceptual analysis approach, this study explores how identity has been conceptualized in the information behaviour literature. Findings indicate that researchers have employed three main approaches when conceptualizing identity: identity as personal project, identity and social groups, and identity as selfpresentation were the three most common conceptualizations of identity. The findings contribute to the identification of the key factors of information behaviour and suggest areas for future research.
\end{abstract}

\section{Introduction}

This study explores how identity has been conceptualized in the information behaviour literature. The study of identity in relation to information behaviour provides a way to explore individuals' and groups' understanding, assumptions and implicit theories of information and how this relates to their information practices. Understanding how information behaviour researchers have conceptualized identity in past research will not only illuminate what is currently known about how people use information to shape their identities and in turn how their identities shape their interactions with information, but it will also suggest areas for future research. Therefore, the present study addresses the following research questions:

1) How have information behaviour researchers conceptualized identity?

2) In what ways have information behaviour researchers characterized the effect of identity on people's information practices?

\section{Literature Review}

Identity can be conceptualized in myriad ways. At its most basic level, identity refers to personal identity, traditionally conceived of as a "subjective individual achievement" (Wetherell 2010, 3). In essence, this understanding conceptualizes identity as that which provides people with their sense of self and a sense of continuity through their lives. This understanding of personal identity, however, has shifted over the past 60 years from a stable and coherent achievement that teenagers undertake as they become adults to mobile, flexible, and negotiated social accomplishments that occur at all stages of one's life and in all contexts. In addition to understanding identity as a personal experience, identity is conceived of as a social occurrence linked to a person's group memberships, i.e., social identity. A person's social identity is linked to social categories, roles, and locations, such as gender, ethnicity, class, or nationality, and the stakes that people have in these categories. Other understandings of identity seek to complicate the apparent binary between personal and social identity. A common approach to this is understanding identity as a discursive construction. This understanding frames identity as a 
subject position either provided to people through dominant social or institutional discourses or a product of localized social interactions. Using a conceptual analysis approach, this study explores how identity has been conceptualized in the information behaviour literature and suggests lines of inquiry for future research.

There have been no comprehensive studies of identity in information behaviour research to date. Bates (2010), however, in a history of information behaviour research did highlight the connection between the emergence of social identity as a focus of societal interest in the 1960s and 1970s and a shift in information behaviour research towards studying specific population groups. Although the influence of social identity on information behaviour was not the focus of these studies, social identity acted as a way to identify populations to study. Or as Bates described it: "many members of the general public had been studied by their social identities the poor, the elderly, etc. - there was a tendency to study information-related behaviour by looking at groups of these sorts" (2383). Other scholars have argued in favor of particular approaches to information research and their ability to illuminate the connections between identity and information practices. Notably, Cox $(2012 ; 2013)$ explored the research possibilities a practice-based approach to information science. He argued that practice approaches to information could use social identity as a way to explore the role of information in larger social practices. This approach, he argued, would shift the focus of information research away from an individualist focus on information needs and expand the way the discipline understands the relational aspects of information and social practices.

\section{Method}

This study used a conceptual analysis approach to examine how identity has been conceptualized by information behaviour researchers. The goal of conceptual analyses is to "improve our understanding of the ways in which particular concepts are (or could be) used for communicating ideas" and to suggest productive lines of work for future research (Furner 2004, 233-234). Following Savolainen (2016), data for this study were collected by conducting a keyword search of core LIS databases: Library and Information Science Source (LISS), Library Literature \& Information Science, and Library, Information Science, and Technology Abstracts (LISTA). The keywords used were "identity," "selfhood," "information behavior/behaviour," and "information practices." The initial search returned 176 articles. The abstracts for each article were reviewed to determine if they were appropriate for inclusion in the study. Inclusion criteria included whether or not the study explicitly examined identity or selfhood as it related to information behaviour or practices. After this initial review, 99 articles were removed from the study. A second review of the full-text of each article was then conducted. Following that, an additional 42 articles were excluded. The final data set consisted of 18 articles. The articles that remained in the study included theoretical explorations of new approaches to LIS research (Cox 2012) and empirical studies of information practices (see for example, Sundin 2002) and consisted of conference papers and peer-reviewed articles.

Data from each article was first recorded using a data abstraction sheet. For each article the full citation, study aim, methodological approach, study design, definition or characterization of identity, and results (as they related to identity) were recorded. Whenever possible, direct quotes from each article were used when abstracting the data. This ensured relevant portions of the text, 
at the paragraph and sentence level, were highlighted for additional analysis and close reading "in order to identify individual characterizations or definitions of [identity]" (Savolainen 2016, 53). Initially, Wetherell's $(2010,5)$ description of how identity has been "understood, defined, framed, and debated" in various scholarly fields and conversations was used to code the conceptualizations of identity in the data set. She identified four approaches to identity: Identity as personal project; identity and social groups; fragmented discursive subjects; and intersectional, hybrid and global identities. As the analysis progressed an additional coding category was added: identity as self-presentation.

\section{Results}

Identity as personal project, identity and social groups, and identity as self-presentation were the three most common conceptualizations of identity. Studies that conceptualized identity as personal project focused on how individual's information behaviours (including search and information avoidance) supported and reflected their self-perception and expression (Buchanan \& Tuckerman 2016; Meyers 2009). Conceptually, identity as personal project shared much in common with identity as self-presentation; however, while the information behaviours associated with personal identity were largely focused on learning more about, or seeking a reflection of, the self, information behaviours associated with self-presentation were largely focused on using information as a way to display one's identity to others (AL Omar \& Cox 2016; Bronstein 2013). When identity was connected to social groups the focus was on how information behaviours supported one's self-definition in relation to others (Cox 2012; Sundin 2002) or how information behaviours acted as a tool for community building and boundary setting (Lingel \& boyd 2013; Rothbauer 2004). The remaining two conceptualizations of identity (discursive and intersectional) were often acknowledged by the authors as potentially influencing information behaviours; however, they were rarely the focus of study. However, Cox (2013) did offer a discourse-inspired approach to conceptualizing identity in his exploration of practice theory as an approach LIS scholar should adopt to understand the role information plays in social practices.

\section{Conclusion}

This study contributes to the information behaviour research by illuminating how a key concept for the field of information studies is conceptualized. Scholars have noted that a lack of clarity about foundational concepts is a significant concern for information science as a discipline (Fleming-May 2014; Pilerot 2012; Savolainen 2016; Yu 2012). Core concepts, such as information need, information sharing, and information use are vague, have "multiple meanings" (Savolainen 2016, 52) and are used in a "cursory manner with ad hoc connotations" (Yu 2012, 2). Clarifying the meaning of a concept can shed light onto the theoretical foundations of a discipline and contribute to the field's empirical knowledge-base (Fleming-May 2014). Identity is a core concept for information behaviour research, especially as it relates to affective information activities and practices. Discursive and intersectional conceptualizations of identity offer exciting opportunities for information researchers to go beyond treating identity as an analytical lens for findings and include the information behaviours of people whose identities are not currently well captured in the information behaviour literature. 


\section{Reference List:}

AL-Omar, M., \& Cox, A. M. (2016). Scholars' research-related personal information collections: A study of education and health researchers in a Kuwaiti University. Aslib: Journal of Information Management, 68, 155-173.

Bates, M. J. (2010). Information behavior. In M. J. Bates \& M. N. Maack (Eds.), Encyclopedia of Library and Information Science (pp. 2381-2391). New York, NY: CRC Press.

Bronstein, J. (2013). Personal blogs as online presences on the internet: Exploring selfpresentation and self-disclosure in blogging. Aslib Proceedings, 65, 161-181.

Buchanan, S., \& Tuckerman, L. (2016). The information behaviours of disadvantaged and disengaged adolescents. Journal of Documentation, 72 (3) 527-548.

Cox, A. M. (2012). An exploration of the practice approach and its place in information science. Journal of Information Science, 38, 176-188. doi: 10.1177/0165551511435881

Cox, A. M. (2013). Information in social practice: A practice approach to understanding information activities in personal photography. Journal of Information Science, 39, 6172. doi: $10.1177 / 0165551512469767$

Fleming-May, R. A. (2014). Concept analysis for library and information science: Exploring usage. Library \& Information Science Research, 36, 203-210.

Furner, J. (2004). Conceptual analysis: A method for understanding information as evidence, and evidence as information. Archival Science, 4, 233-265.

Lingel, J., \& boyd, d. (2013). "Keep it secret, keep it safe": Information poverty, information norms, and stigma. Journal of the American Society for Information Science and Technology, 65, 981-991.

Meyers, E. M. (2009). Tip of the iceberg: Meaning, identity, and literacy in preeteen virtual worlds. Journal of Education for Library and Information Science, 50, 226-236.

Pilerot, O. (2012). LIS research on information sharing activities: People, places, or information. Journal of Documentation, 68, 559-581. http://dx.doi.org/10.1108/00220411211239110.

Rothbauer, P. (2004). "People aren't afraid anymore, but it's hard to find books": Reading practices that inform the personal and social identities of self-identified lesbian and queer young women. The Canadian Journal of Information and Library Science, 28(3), 53-74.

Savolainen, R. (2016). Approaches to socio-cultural barriers to information seeking. Library \& Information Science Research, 38, 52-59. doi: 10.1016/j.lisr.2016.01.007 
Sundin, O. (2002). Nurses' information seeking and use as participation in occupational communities. New Review of Information Behaviour Research, 3, 187-202.

Wetherell, M. (2010). The field of identity studies. In M. Wetherell \& C. T. Mohanty (Eds.), The SAGE handbook of identities (pp. 3-26). London, England: Sage.

Yu, L. (2012). Towards a reconceptualization of the 'information worlds of individuals. Journal of Librarianship and Information Science, 44, 3-18. http://dx.doi.org/10. $1177 / 0961000611424586$. 